Introduction: Many early-stage breast cancers are not palpable and thus must be localized before surgery. Detecting these lesions is crucial before they become clinically symptomatic to avoid morbidity and mortality. Nowadays, there are several new alternative techniques to traditional needle/wire localization available. These methods allow for better surgical margins, decreased costs and operating room delays, as well as improved patient satisfaction. The purpose of this study is to evaluate the nonradioactive inducible magnetic seed system Magseed (Endomagnetics Ltd, Cambridge, UK) for preoperative localization of nonpalpable breast lesions. To our knowledge, this report documents the first clinical experience with Magseed in Poland. Material and methods: A single-institution case report of 10 women with nonpalpable breast lesions localized and excised by using the Magseed surgical guidance system between November 2017 and May 2018.

Results and conclusions: Magseed is an easy, sensitive and effective localization method. It is beneficial for oncoplastic outcomes and for scheduling efficiency, which overcomes many limitations of other localization methods. Surgical specimen margins were evaluated in $90 \%$ of cases as negative, with no additional re-excision. Only one patient with ductal carcinoma in situ had a positive tumor margin at the axillary side.

Key words: Magseed, impalpable breast cancer, localization techniques, margin rate.

Contemp Oncol (Pozn) 2020; 24 (1): 51-54 DOI: https://doi.org/10.5114/wo.2020.93677

\section{Evaluation of the nonradioactive inducible magnetic seed system Magseed for preoperative localization of nonpalpable breast lesions - initial clinical experience}

\author{
Karolina Pieszko ${ }^{1,2}$, Mateusz Wichtowski ${ }^{1}$, Marcin Cieciorowski ${ }^{1}$, \\ Robert Jamont $^{2}$, Dawid Murawa ${ }^{1}$ \\ ${ }^{1}$ Clinic of General Surgery and Surgical Oncology, Faculty of Medicine \\ and Health Sciences, University of Zielona Gora, Poland \\ ${ }^{2}$ Department of Plastic Surgery and Burns, Hospital in Nowa Sol, Poland
}

\section{Introduction}

Wire localization (WL) is a needle method for locating lesions in the breast. It has been used as a standard of preoperative image-guided localization of non-palpable breast lesions since the early 1970s. The wire is placed on the same day as a surgical breast excision using ultrasound, mammography, magnetic resonance imaging (MRI) or computed tomography (CT). This technique limits radiological and surgical schedules in the early mornings [1-3]. It also requires following the dissection route as designed, which should not be changed. The wire can protrude from the patient's skin, which will cause displacement. Besides its disadvantages, in many institutions it remains the primary technique because of low cost and accessibility worldwide. The rate of positive margins for wire localizations ranges from $20 \%$ to $70 \%$ [4]. Finally, some investigations have started to find better alternative localization techniques.

The first non-wire system was radio-guided localization $(R G L)$ in the form of radio-guided occult lesion localization (ROLL) using radiolabeled albumin-based colloid with TC-99m injected into the tumor under ultrasound and stereotactic guidance. ROLL was first described as a possible alternative to WL in 1996 [5]. The second RGL method, known as radio-guided seed localization (RSL), was reported by Gray et al. in 2001 [6]. RSL uses a titanium seed radiolabeled with $1-125$ inserted into the tumor using the same guidance as ROLL. RGL overcomes many of the disadvantages of WL [7]. TC-99m, as well as 1-125, can be placed before the day of surgery and detected by the handheld gamma probe to guide intra-operative identification and surgical resection [8]. Nevertheless, these techniques require a strict nuclear regimen, which is the main limitation for hospitals. It has been demonstrated that the method causes less pain and greater overall convenience for patients [9]. RSL has advantages over ROLL such as the possibility of mammographic or ultrasound confirmation of the site of implantation in relation to the tumor after placement of the 1-125 seed and improvement in logistics of the operative planning because of I-125's long half-life of 60 days compared to the TC-99m radioisotope, which requires injection into the tumor bed within 24 h of surgery [10]. The tumor-free margin rates range from $73 \%$ to $92.8 \%$ with RSL $[7,11]$. In cases in which ROLL was performed, the tumor-free margin rate was $82.5-90 \%$. Re-excision rates range from $7.2 \%$ to $21 \%$ with RSL, $12 \%$ to $25 \%$ with WL and $10.9 \%$ with ROLL [7, 12-14].

Recently, two new nonradioactive technologies have been developed for nonpalpable breast lesions. Both have received clearance from the Food and Drug Administration: SAVI SCOUT in August 2014 and Magseed in April 
2016. The SAVI SCOUT (Cianna Medical, Aliso Viejo, California) uses a radar wave reflector which is activated with infrared light. The $12 \mathrm{~mm}$ radar wave-reflective device is percutaneously placed under imaging guidance (ultrasound or mammogram) up to 7 days before surgery. Mango et al. reported clear margins in a total of 8 bracketed cases [15]. The re-excision rates from initial publications with SAVI SCOUT range from 0\% to $18.5 \%$. Disadvantages of the technique include the possibility of nondetection after placement (2.0-2.5\%) and that it cannot be placed at greater than $45 \mathrm{~mm}$ depth $[16,17]$.

Magseed (Endomag, Austin, TX) is a $1 \mathrm{~mm} \times 5 \mathrm{~mm}$ magnetic metallic marker, which is preloaded within a sterile 18-G needle and inserted into the lesion up to $30 \mathrm{~mm}$ depth under mammographic or ultrasound guidance up to 30 days before surgery $[18,19]$. The procedure is performed under local anesthesia. Immediately after, a mammogram confirms appropriate positioning. The seed is detectable using the Sentimag probe in the same way as the Sienna+ tracer in sentinel lymph node (SNL) biopsy. It can be detected from any direction, regardless of seed orientation. The Sentimag probe produces an alternating magnetic field which transiently magnetizes the iron oxide particles within the Magseed [20]. The probe shows a numerical count and produces an audio tone, which is related to the strength of the magnetic field and therefore to the distance of the seed in the tumor from the detector probe. Bracketing may be performed as long as the seeds are placed greater than $20 \mathrm{~mm}$ from one another. The seed is cylindrical with no barbs, has no moving parts and cannot be damaged when implanted [21]. The main advantage of the Magseed and SAVI SCOUT is that there is no associated radiation like that associated with radioactive seed localization. All the most important characteristics of these methods are presented in Table 1.

\section{Material and methods}

The current lesion localization techniques in the Department of General and Minimally Invasive Surgery,
Baptism of Poland Memorial Hospital in Gniezno, Poland, where the study was conducted, are WL and ROLL. On average, ROLL technique requires 60 min for placement one day before surgery and WL is placed in the early morning just before the surgery. Our surgeons have experience in all of these methods. Between November 2017 and May 2018, we scheduled 10 patients for the Magseed localization procedure. The mean patient age at the time of localization was 60.6 (range, 42-79 years) and the mean BMI was 27.74 (range 24-39.3).

All Magseed markers (Endomagnetics Ltd, Cambridge, UK) were inserted with 18-gauge needle deployment under local anesthesia into the center of the target lesions under ultrasound guidance. The nonpalpable breast lesion on the left and the Magseed insertion process on the right are presented as an ultrasound image in Figure 1. Each procedure treated 1 lesion with 1 seed. The Magseed was placed in 100\% of cases where intended and was simple to maneuver. On average, Magseed placement took 7.5 min. All seeds were placed successfully, and no seed migration was noted. The approximate depth of placement in post-insertion ultrasound was in 50\% patients less than $30 \mathrm{~mm}$ and in the other $50 \%$ greater than $30 \mathrm{~mm}$. In all cases of Magseed use, ultrasound was performed intraoperatively and confirmed Magseed findings in $100 \%$ of cases. The technique was evaluated by surgeons as easier than WL and ROLL. On average, from incision until specimen removal, it took 13.5 min. In 8/10 patients (80\%) Sienna+ was used for SLN localization and in this group of patients in $5 / 8$ cases $(62.5 \%)$ the lesion was removed first before the nodes. The mean distance between the closest lesion and the Sienna+ injection site was $33.1 \mathrm{~mm}$ (range 20-45 mm). All Siena+ injections were subareolar, performed one day before the surgery, and were detectable with Sentimag through the skin. The mean number of removed sentinel nodes was 1.9 (range 1-3) and the mean Sienna+ count of the highest sentinel was 3738.75 (range 750-7600). No complication after the procedure was reported.

Table 1. Preoperative localization methods of nonpalpable breast lesions and surgical outcomes

\begin{tabular}{|c|c|c|c|c|}
\hline Method & $\begin{array}{c}\text { Type of inserted } \\
\text { material }\end{array}$ & $\begin{array}{l}\text { Positive margin } \\
\text { rates }(\%)\end{array}$ & Advantages & Disadvantages \\
\hline WL & Stainless steel wire & $20-70[11]$ & Low cost & $\begin{array}{c}\text { Placement on the same day as surgery } \\
\text { Painful } \\
\text { Possibility of protrusion and displacement } \\
\text { Surgical positioning } \\
\text { Worse oncoplastic effect }\end{array}$ \\
\hline ROLL & $\begin{array}{l}\text { Radiolabeled albumin- } \\
\text { based colloid with } \\
\text { TC-99m }\end{array}$ & $10-18.5$ [7] & Placement within $24 \mathrm{~h}$ of surgery & Nuclear regimen \\
\hline RSL & $\begin{array}{l}\text { Titanium seed } \\
\text { radiolabeled with I-125 }\end{array}$ & $7.2-27[7,11]$ & $\begin{array}{l}\text { Placement before the day } \\
\text { of surgery }\end{array}$ & Nuclear regimen \\
\hline $\begin{array}{l}\text { SAVI } \\
\text { SCOUT }\end{array}$ & Wire-free radar & $\begin{array}{l}10.3-15 \\
{[23,24]}\end{array}$ & $\begin{array}{l}\text { Placement up to } 7 \text { days before } \\
\text { surgery } \\
\text { Nonradioactive technology }\end{array}$ & $\begin{array}{c}\text { Cannot be placed at greater than } 45 \mathrm{~mm} \\
\text { depth }\end{array}$ \\
\hline Magseed & $\begin{array}{l}\text { Magnetic metallic } \\
\text { marker }\end{array}$ & $7.5[25]$ & $\begin{array}{c}\text { Placement up to } 30 \text { days before } \\
\text { surgery } \\
\text { Nonradioactive technology }\end{array}$ & $\begin{array}{l}\text { Sensing depth } 30 \mathrm{~mm} \text { [18] } \\
\text { Bracketing seeds greater than } 20 \mathrm{~mm} \text { [21] }\end{array}$ \\
\hline
\end{tabular}



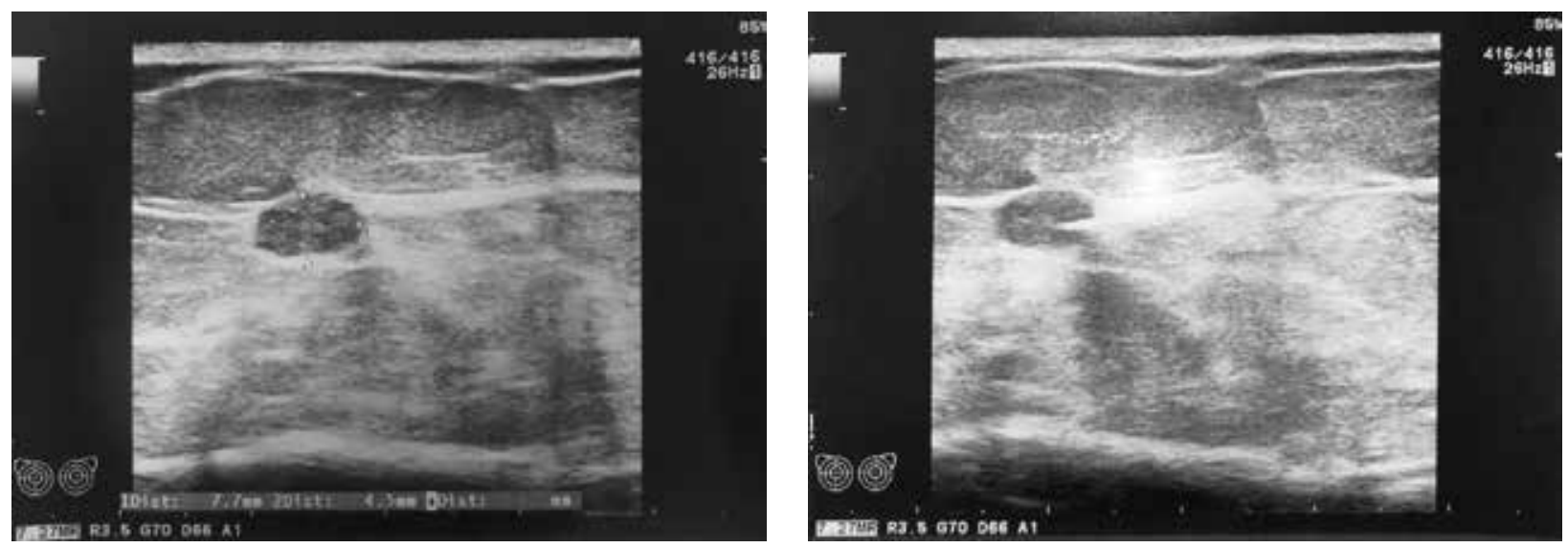

Fig. 1. Nonpalpable breast lesion on the left and the Magseed insertion process on the right ultrasound image

As presented in Table 2, wide local excision was performed in $100 \%$ of cases (10/10). The pathological examination found malignant lesions (9/10) in the majority of cases. In total, there was 50\% invasive ductal carcinoma and $40 \%$ ductal carcinoma in situ. One patient had benign pseudoangiomatous stromal hyperplasia. Surgical specimen margins were evaluated in $90 \%$ as negative, with no additional re-excision. Only one patient with ductal carcinoma in situ had a positive tumor margin at the axillary side. No Magseed displacement was observed, and all seeds were removed intact, as shown on histology from 10 breasts.

\section{Results and discussion}

The findings of this single-center case study of Magseed demonstrate that it is an easy, sensitive and effective localization method. It improved scheduling efficiency and patient comfort. In comparison with needle techniques, there is no need to cut exactly where the needle was inserted, which influences the oncoplastic outcome. Although the primary goal of breast-conserving surgery is to achieve negative margins, the cosmetic outcome is essential for the patient's quality of life. Co-usage of Magseed and Sienna+ was successful in 100\% of cases and all surgeons asked in the survey would like to use them together again. Ease of placing a magnetic marker, its detection and margin rate results seem to be more beneficial than the isotopic technique used before. In our clinical practice, all seeds at all depths in the breast were detectable using the Sentimag probe intraoperatively. As well as Magseed, Sienna+ is nonradioactive, so they do not need to use special nuclear regimens, which allows more surgical centers to localize lesions and operate on them. Furthermore, the surgeons who inserted the seeds found it easy and similar to the insertion of a conventional biopsy marker. The disadvantage of this method is the price itself, but the total cost of nuclear requirement, operation delays and finally surgical outcome is thought-provoking. The limitation to the Magseed system may be placing a seed into the lesion at a depth greater than $4 \mathrm{~cm}$. Also, the signals from multiple seeds placed in close proximity $(<2 \mathrm{~cm})$ can be challenging to separate [22]. Our findings regarding the
Table 2. Surgical outcomes

\begin{tabular}{|c|c|c|}
\hline Parameter & $\begin{array}{c}\text { Surgical } \\
\text { outcomes }\end{array}$ & $\begin{array}{c}\text { Number (\%) } \\
\text { of lesions }\end{array}$ \\
\hline \multirow{5}{*}{$\begin{array}{l}\text { Surgical } \\
\text { pathologic } \\
\text { findings }\end{array}$} & Benign & \\
\hline & PSH & $1(10)$ \\
\hline & Malignant & $9(90)$ \\
\hline & IDC & $5(50)$ \\
\hline & DCIS & $4(40)$ \\
\hline \multirow[t]{2}{*}{ Surgical margins } & Negative & $9(90)$ \\
\hline & Positive & $1(10)$ \\
\hline
\end{tabular}

re-excision rate appear to be comparable to those reported in a prospective study on 200 patients with non-palpable invasive and in-situ breast carcinoma by Zacharioudakis et al. [23] where the same rate in the Magseed cohort was $16 \%$ and in the WL cohort was $14 \%$. In another study evaluating Magseed localization of 73 nonpalpable breast lesions, there were positive margins in $12 \%$ of cases [22].

\section{Conclusions}

Undoubtedly, current knowledge about this magnetic marker is limited, but early clinical experience suggests that Magseed is effective for preoperative localization of nonpalpable breast cancer. Therefore, reporting and more analytical studies will provide better evidence in the future.

The authors declare no conflict of interest.

\section{References}

1. Ahmed M, Rubio IT, Klaase JM, Douek M. Surgical treatment of nonpalpable primary invasive and in situ breast cancer. Nat Rev Clin Oncol 2015; 12: 645-663.

2. Goudreau SH, Joseph JP, Seiler SJ. Preoperative Radioactive Seed Localization for Nonpalpable Breast Lesions: Technique, Pitfalls, and Solutions. Radiographics 2015; 35: 1319-1334.

3. Pouw B, de Wit-van der Veen LJ, Stokkel MP, Loo CE, Vrancken Peeters MJ, Valdés Olmos RA. Heading toward radioactive seed lo- 
calization in non-palpable breast cancer surgery? A meta-analysis. J Surg Oncol 2015; 111: 185-191.

4. Besic N, Zgajnar J, Hocevar M, Rener M, Frkovic-Grazio S, Snoj N, Lindtner J. Breast biopsy with wire localization: Factors influencing complete excision of nonpalpable carcinoma. Eur Radiol 2002; 12: 2684-2689.

5. van der Ploeg IMC, Hobbelink M, van den Bosch MA, Mali WP, Borel Rinkes $\mathrm{IH}$, van Hillegersberg R. "Radioguided occult lesion localisation" (ROLL) for non-palpable breast lesions: A review of the relevant literature. Eur J Surg Oncol 2008; 34: 1-5.

6. Johnson RB, Sun XL, Hockman MA, et al. Randomized prospective evaluation of a novel technique for biopsy or lumpectomy of nonpalpable breast lesions: Radioactive seed versus wire localization. Ann Surg Oncol 2001; 8: 711-715.

7. Van Der Noordaa MEM, Pengel KE, Groen E, van Werkhoven E, Rutgers EJ, Loo CE, Vogel W, Vrancken Peeters MJ. The use of radioactive iodine-125 seed localization in patients with non-palpable breast cancer: A comparison with the radioguided occult lesion localization with 99m technetium. Eur J Surg Oncol 2015; 41: 553558.

8. Lovrics PJ, Cornacchi SD, Vora R, Goldsmith CH, Kahnamoui K. Systematic review of radioguided surgery for non-palpable breast cancer. Eur J Surg Oncol 2011; 37: 388-397.

9. Bloomquist E V, Ajkay N, Patil S, Collett AE, Frazier TG, Barrio AV. A Randomized Prospective Comparison of Patient-Assessed Satisfaction and Clinical Outcomes with Radioactive Seed Localization versus Wire Localization. Breast J 2016; 22: 151-157.

10. Harvey JR, Lim Y, Murphy J, Howe M, Morris J, Goyal A, Maxwell AJ. Safety and feasibility of breast lesion localization using magnetic seeds (Magseed): a multi-centre, open-label cohort study. Breast Cancer Res Treat 2018; 169: 531-536.

11. Sharek D, Zuley ML, Zhang JY, Soran A, Ahrendt GM, Ganott MA. Radioactive seed localization versus wire localization for lumpectomies: A comparison of outcomes. Am J Roentgenol 2015; 204: 872-877.

12. Langhans L, Tvedskov TF, Klausen TL, et al. Radioactive Seed Localization or Wire-guided Localization of Nonpalpable Invasive and In Situ Breast Cancer. Ann Surg 2017; 266: 29-35.

13. Zhang Y, Seely J, Cordeiro E, et al. Radioactive Seed Localization Versus Wire-Guided Localization for Nonpalpable Breast Cancer: A Cost and Operating Room Efficiency Analysis. Ann Surg Oncol 2017; 24: 3567-3573.

14. Theunissen CIJM, Rust EAZ, Edens MA, Bandel C, Van't Ooster-van den Berg JG, Jager PL, Noorda EM, Francken AB. Radioactive seed localization is the preferred technique in nonpalpable breast cancer compared with wire-guided localization and radioguided occult lesion localization. Nucl Med Commun 2017; 38: 396-401.

15. Mango VL, Wynn RT, Feldman S, Friedlander L, Desperito E, Patel SN, Gomberawalla A, Ha R. Beyond Wires and Seeds: Reflector-guided Breast Lesion Localization and Excision. Radiology 2017; 284: 365-371.

16. Mango V, Ha R, Gomberawalla A, Wynn R, Feldman S. Evaluation of the SAVI SCOUT Surgical Guidance System for Localization and Excision of Nonpalpable Breast Lesions: A Feasibility Study. AJR Am J Roentgenol 2016; 207: W69-W72.

17. Cox CE, Russell S, Prowler V, et al. A Prospective, Single Arm, Multisite, Clinical Evaluation of a Nonradioactive Surgical Guidance Technology for the Location of Nonpalpable Breast Lesions during Excision. Ann Surg Oncol 2016; 23: 3168-3174.

18. Sentimag ${ }^{\circledR} /$ Magseed ${ }^{\circledR}$ for magnetic lesion localisation. 2017: 52726. Available at: https://www.sysmex-europe.com/products/ sentimag-magseed-in-breast-cancer-4395.html

19. Hayes MK. Update on Preoperative Breast Localization. Radiol Clin North Am 2017; 55: 591-603.

20. Hersi AF, Eriksson S, Ramos J, Abdsaleh S, Wärnberg F, Karakatsanis A. A combined, totally magnetic technique with a magnetic marker for non-palpable tumour localization and superparamagnetic iron oxide nanoparticles for sentinel lymph node detection in breast cancer surgery. Eur J Surg Oncol 2019; 45: 544-549.

21. Greenwood HI, Dodelzon K, Katzen JT. Impact of Advancing Technology on Diagnosis and Treatment of Breast Cancer. Surg Clin North Am 2018; 98: 703-724.
22. Price ER, Khoury AL, Esserman LJ, Joe BN, Alvarado MD. Initial Clinical Experience With an Inducible Magnetic Seed System for Preoperative Breast Lesion Localization. AJR Am J Roentgenol 2018; 210 : 913-917.

23. Zacharioudakis K, Down S, Bholah Z, Lee S, Khan T, Maxwell AJ, Howe M, Harvey J. Is the future magnetic? Magseed localisation for non-palpable breast cancer. A multi-centre non randomised control study. Eur J Surg Oncol 2019; 45: 2016-2021.

24. Jadeja PH, Mango V, Patel S, et al. Utilization of multiple SAVI SCOUT surgical guidance system reflectors in the same breast: A single-institution feasibility study. Breast J 2018; 24: 531-534.

25. Singh P, Scoggins M, Sahin A, et al. Effectiveness and Safety of Magseed-localization for Excision of Breast Lesions: A Prospective Clinical Trial Disclosures. ACS Quality and Safety Conference, July 19-22, 2019, Washington DC.

\section{Address for correspondence}

\section{Karolina Pieszko}

Clinic of General Surgery and Surgical Oncology

Faculty of Medicine and Health Sciences

University of Zielona Gora

28 Zyty St.

65-046 Zielona Góra, Poland

e-mail: saurie@gmail.com

Submitted: 24.10 .2019

Accepted: 2.12.2019 